\title{
Digitally manipulating memory: Effects of doctored videos and imagination in distorting beliefs and memories
}

\author{
Robert A. NASH ANd Kimberley A. WAde \\ University of Warwick, Coventry, England \\ AND \\ D. STEPHEN LINDSAY \\ University of Victoria, Victoria, British Columbia, Canada
}

\begin{abstract}
In prior research on false autobiographical beliefs and memories, subjects have been asked to imagine fictional events and have been exposed to false evidence that indicates that the fictional events occurred. But what are the relative contributions of imagination and false evidence toward false belief and memory construction? In the present study, subjects observed and copied various simple actions; then they viewed doctored videos that suggested that they had performed extra actions and they imagined performing some of those and some other actions. Subjects returned 2 weeks later for a memory test. False evidence or imagination alone was often sufficient to cause belief and memory distortions; in combination, they appeared to have additive or even superadditive effects. The results bear on the mechanisms underlying false beliefs and memories, and we propose legal and clinical applications of these findings.
\end{abstract}

Memory scientists have amply demonstrated the malleability of people's memories for nonrecent (e.g., Lindsay, Hagen, Read, Wade, \& Garry, 2004; E. F. Loftus \& Pickrell, 1995) and recent (e.g., E. F. Loftus \& Palmer, 1974; Thomas \& Loftus, 2002) events. Although methodologies have varied from study to study, a substantial number of false memory experiments show that the act of imagining is key to false memory development (Goff \& Roediger, 1998; Hyman, Husband, \& Billings, 1995; Mazzoni \& Memon, 2003). Yet current research suggests that fabricated evidence can produce a similar response (Garry \& Wade, 2005; Nash \& Wade, 2009; Wade, Garry, Read, $\&$ Lindsay, 2002). In the present study, we examine how imagination and false evidence work individually and in combination to produce false beliefs and false memories.

\section{Source Monitoring}

Johnson and colleagues' source-monitoring framework (SMF) can be used to make predictions about a wide range of false memory phenomena (Johnson, Hashtroudi, \& Lindsay, 1993; Johnson \& Raye, 1981; Lindsay, 2008). According to the SMF, remembering is an inferential process: People must attribute mental experiences, such as thoughts, images, and feelings, to particular origins (although, typically, such attributions are made quickly and without conscious deliberation). False memories arise when mental events from one source are misattributed to another (erroneous) source. People can make source judgments by relying on environmental cues (e.g., official records and documentation; see Wade \& Garry, 2005) and various qualitative and quantitative cues from memory itself. For instance, real memories typically contain more sensory information (such as smells, sounds, and visual details) and more contextual cues (information about the time and location) than do imagined events (Johnson, Foley, Suengas, \& Raye, 1988). Real memories often also contain details that act as a marker of their veracity; for instance, one would expect a real memory of a conversation with a friend to contain auditory records of the friend's voice rather than another person's voice. However, sourcemonitoring errors can occur when internally generated images are rich with memory-like characteristics such as vivid sensory detail and event-consistent information.

\section{Laboratory-Based False Memories}

Memory scientists have developed numerous paradigms for examining false memory phenomena in the laboratory (for partial reviews, see Pezdek \& Lam, 2007; Wade et al., 2007). Some studies have distorted memories for nonautobiographical experiences (e.g., Deese/RoedigerMcDermott [DRM] studies, Roediger \& McDermott, 1995), whereas others have distorted memories for self-involving, moderately significant autobiographical experiences (e.g., Desjardins \& Scoboria, 2007). The latter literature reveals two techniques that are commonly used to induce false memories: encouraging individuals to imagine counterfac-

K. A.Wade, k.a.wade@warwick.ac.uk 
tual events and presenting individuals with false evidence that implies that the counterfactual events occurred.

With respect to imagination, we know that merely imagining a fictitious event can lead people to report that they remember doing something that they never did (Garry, Manning, Loftus, \& Sherman, 1996; Hyman \& Pentland, 1996; Mazzoni \& Memon, 2003; Pezdek, Blandon-Gitlin, \& Gabbay, 2006). Goff and Roediger (1998), for instance, found that the more times that subjects imagined performing nonperformed actions, the more likely they were to claim that they had performed them (see also Johnson, Raye, Wang, \& Taylor, 1979). Indeed, this imagination inflation effect is a robust phenomenon (Garry \& Polaschek, 2000).

With regard to effects of false evidence, recent research reveals that such information can distort memory. Bernstein, Laney, Morris, and Loftus (2005b) gave some adults false feedback that suggested that they had gotten sick as children from eating hard-boiled eggs, and approximately $25 \%$ reported a specific belief or memory for the fictitious event. In a follow-up study, food-related false memories caused people to avoid certain foods later on (Geraerts et al., 2008). Wade and colleagues showed that fake photographs can also induce false memories (Garry \& Wade, 2005; Wade et al., 2002). They gave adults photographs of themselves as children and asked them to recall the events depicted in each photo. Unbeknownst to the subjects, the experimenters faked one of the photos by digitally pasting a childhood image of the subject into a hot-air balloon scene. After working at remembering the pseudoevent for 1 week, exactly half of the subjects came to falsely recall aspects of the balloon ride. Together, these false evidence studies illustrate the powerful impact that environmental influences can have on memory.

Why do imagination and false evidence distort our beliefs and memories? Imagination, according to the SMF, promotes perceptual and contextual details in mental imagery. When we imagine a counterfactual experience, we embellish that event with details that are characteristic of a real memory, causing the imagined event to seem phenomenologically similar to a real memory. In line with this account, imagined events are more often misremembered as actual events by individuals with good imagery (Johnson et al., 1979), or if the events are inherently easy to imagine (Finke, Johnson, \& Shyi, 1988), or if conditions lead subjects to include sensory details in their imaginings (Thomas, Bulevich, \& Loftus, 2003).

From an SMF perspective, false evidence might foster false memories in three qualitatively different ways. First, analogous to imagination, false evidence may reduce differences between imagined events and real memories by providing fluent perceptual details that can be combined with products of imagination. In Lindsay et al. (2004), for example, subjects worked at remembering a childhood prank that they and a classmate had supposedly played (but that almost certainly had not really happened - namely, putting Slime in their teacher's desk). Half of the subjects were given their real class-group photo for that school year to use as a "memory cue." False memories were twice as common among subjects who were given the class photo. Lindsay et al. speculated that one mechanism for this ef- fect was that the photo enabled subjects to form vivid and perceptually detailed images of their teachers, their classmates, and themselves that could be combined with products of imagination to create compelling false memories.

False evidence may also foster false memories by increasing the perceived plausibility of the suggested event. Individuals are unlikely to develop false memories, unless they accept the suggested event as something that could plausibly have happened (Hart \& Schooler, 2006; Johnson \& Raye, 2000; Mazzoni \& Kirsch, 2002; Pezdek, Finger, \& Hodge, 1997; for a discussion of social-influence processes by which implausible ideas can come to seem plausible, see Lynn, Pintar, Stafford, Marmelstein, \& Lock, 1998). To the extent that it is persuasive, false evidence, by definition, increases the perceived plausibility of the suggested event.

Finally, false evidence might encourage people to lower their criteria for believing that a particular event occurred and for the amount of detail a mental image of that event must possess before treating it as a memory (Mazzoni \& Kirsch, 2002). Put differently, even if seeing a doctored video has no effect upon the perceptual detail of a person's mental imagery or the plausibility of the suggestion, it might nevertheless make a person willing to attribute somewhat less vivid images of suggested events to memory.

In sum, previous research leads us to believe that imagination and false evidence are powerful forms of suggestion. What we do not know, however, is the individual and combined effects of these two influences. Almost all false evidence studies have confounded false evidence with imagination. In the sole exception of which we are aware, Bernstein, Laney, Morris, and Loftus (2005a) gave subjects false feedback that they had become sick from eating strawberry ice cream and encouraged half of the subjects to imagine what might have happened. Although the false feedback alone increased subjects' confidence that the suggested event occurred, imagination further increased their confidence. This research suggests that imagination and false evidence might have unique effects on subjects' beliefs, but because the authors did not independently manipulate these two factors, we cannot say with certainty what the separate and combined effects might be.

In the present experiments, we developed a novel procedure for assessing the effects of imagination and false evidence on beliefs and memories. Subjects observed and copied various simple actions and then viewed doctored videos that suggested that they had performed extra actions; they also imagined performing some of the actions in the doctored video and some other nonperformed actions. Finally, subjects returned 2 weeks later for a memory test.

\section{EXPERIMENT 1}

Experiment 1 addressed three research questions. First, can doctored video evidence alone change individuals' beliefs and memories about their recent experiences? At least one study (Bernstein et al., 2005a) has shown that false evidence alone can distort people's beliefs about childhood experiences, so we predicted that subjects would be more certain that they performed critical actions 
shown in the doctored video than those not in the video. Second, which technique, imagination or false evidence, has a greater distortive influence? Because most studies have confounded the two techniques, we had no theoretical reason to predict that one would be more powerful than the other. Finally, what is the combined effect of imagination and false evidence? The answer to this question would allow us to speculate about the cognitive mechanisms that drive the false evidence effect.

We had a secondary interest in determining whether imagination and false evidence influence beliefs and memories of both memorable and less memorable actions. Several studies have investigated the effects of imagining different types of actions by manipulating the bizarreness of the actions (e.g., Seamon, Philbin, \& Harrison, 2006), on the basis of the reasoning that people should be more capable of rejecting bizarre false events than familiar ones. Some researchers more broadly discuss "memorability-based strategies" that incorporate numerous possible characteristics, including bizarreness, that might help a person to reject a false suggestion (Ghetti, 2003; Tousignant, Hall, \& Loftus, 1986). In Experiment 1, therefore, we manipulated the memorability of the critical actions to explore this issue. It is worth noting, however, that the memorability of these actions is likely to be highly correlated with their bizarreness as well as with similar characteristics.

\section{Method}

\section{Subjects and Design}

Forty-seven University of Victoria (Canada) undergraduates received optional bonus points in a psychology course for individually participating in three sessions over $11-21$ days $(M=14.55$ days, $S D=2.58) .{ }^{1}$ We used a 2 (video vs. no video) $\times 2$ (imagined vs. not imagined) within-subjects design. The procedure is outlined in Appendix A.

\section{Materials and Procedure}

Selecting the critical and noncritical actions. We selected 37 actions such as flip the coin and put on the hat. Of those, 16 were taken from Goff and Roediger (1998), 5 (1 familiar and 4 bizarre) were taken from Thomas and Loftus (2002), and 16 were additional actions that we created or adapted (see Appendix B for a full list). We asked 25 volunteers to rate on a 7-point scale (where $1=I^{\prime} d$ easily remember doing this and $7=$ I'd easily forget doing this) how memorable each action would be to somebody who had performed it 2 weeks earlier. On the basis of these ratings, we chose four critical actions that differed in memorability (all $p \mathrm{~s}<.05$ ): kiss the magnifying glass $(M=2.32, S D=1.46)$, rub the $Q$-tip on the toy car $(M=$ $3.32, S D=1.73)$, roll the dice $(M=4.52, S D=1.50)$; and browse the book $(M=5.48, S D=1.16)$. We randomly assigned the critical actions to four within-subjects conditions: video only, imagine only, video + imagine, and control. Critical video actions (i.e., video-only and video+imagine conditions) were actions that subjects would view in a doctored video. Critical imagine actions (i.e., imagine-only and video+imagine conditions) were actions that subjects would imagine performing. Finally, the control action neither appeared in the video nor was imagined. Subjects did not perform the critical actions at any stage. The remaining 33 actions served as noncritical (filler) actions in different stages of the experiment-some were performed in Session 1, some were imagined in Session 2 but not performed, and some were new in Session 3-and ranged in memorability at each session. We had no plans to analyze subjects' rat- ings for the noncritical actions, so we did not counterbalance these actions.

Session 1: Event phase. Subjects were seated at a table opposite a research assistant (RA). They were told that the experimenters were interested in mental imagery and that they would be filmed observing and copying the RA performing some actions. The objects necessary for performing the actions (e.g., a coin, a hat) were arranged on the table: one set for the subject and one set for the RA. Subjects familiarized themselves with the objects, and the remainder of Session 1 was captured on video (see Figure 1 for a representative still depicting the camera's field of view). The RA began by performing an action for $15 \mathrm{sec}$; then, the subject copied the same action for $15 \mathrm{sec}$. A loud beep indicated when the subject and RA should start and stop performing each action. Next, the RA performed a second action, and this process continued until the RA and the subject had performed 26 noncritical actions. All subjects performed the same actions, and these varied with respect to memorability.

Immediately after the subject left, we filmed the RA performing two of the four critical actions that would serve as our doctored video clips in Session 2 (the video+imagine and video-only actions). We created two fake clips by combining these extra video clips with clips of the subject observing the RA at Session 1 (see Figure 1). Note that the fake clips did not show the subject performing the critical actions, only observing the RA perform them. To enhance acceptance of the fake clips, we inserted them into a 5-min sequence made up of 10 untouched clips of the subjects observing the RA perform actions that really had been performed in Session 1. Thus, each subject's video contained twelve 10 -sec clips separated by 15 -sec pauses. Clips 7 and 10 were always the fake clips, and the remaining clips depicted the same noncritical actions for all subjects.

Session 2: Suggestion phase. Session 2 was conducted 2 days later and comprised two tasks. In the first, subjects were exposed to the fake video clips. Subjects were seated in front of a computer and were told that they would watch several video clips of themselves watching the RA perform actions at Session 1. They were instructed to write down at the end of each clip the name of the action that the RA performed. This task ensured that subjects attended to each clip.

For the second task, the subjects were instructed to imagine performing some actions. Subjects were told that an action sentence would appear on the monitor, and their task was to close their eyes and imagine performing that action for $10 \mathrm{sec}$, after which they would hear a beep. To encourage subjects to imagine every action, they were asked to rate the vividness of their images as per Thomas and Loftus (2002). Subjects imagined 15 action sentences, each repeated four times ( 60 actions in total, presented to each subject in the same quasi-random order). Two of the 15 were critical actions: One had been presented in the doctored video (video+imagine), and one had not (imagine only). The remaining 13 actions were noncritical actions ( 9 performed; 4 nonperformed actions intended to make salient to subjects that they did not perform all the imagined actions). The imagination task lasted $15 \mathrm{~min}$.

Session 3: Memory test. Session 3 was conducted approximately 2 weeks after Session 1 . The memory test contained 28 action sentences, including all 4 critical and 24 noncritical actions (17 performed during Session 1, 4 unperformed but imagined in Session 2, and 3 new). Subjects answered two questions (based on Scoboria, Mazzoni, Kirsch, \& Relyea's, 2004, Autobiographical Beliefs and Memory Questionnaire) about each action. First, subjects rated the extent to which they believed they performed each action, using an 8-point scale, where $1=I$ definitely did not do this and $8=I$ definitely did do this. Next, they rated their memory of performing each action, using an 8-point scale, where $1=$ no memory of doing this and $8=$ clear and detailed memory of doing this. Finally, subjects wrote down what they thought the aim of the experiment was, and the experimenter debriefed them. Subjects were also invited to attempt to identify which two actions from the memory test were the critical video actions. 


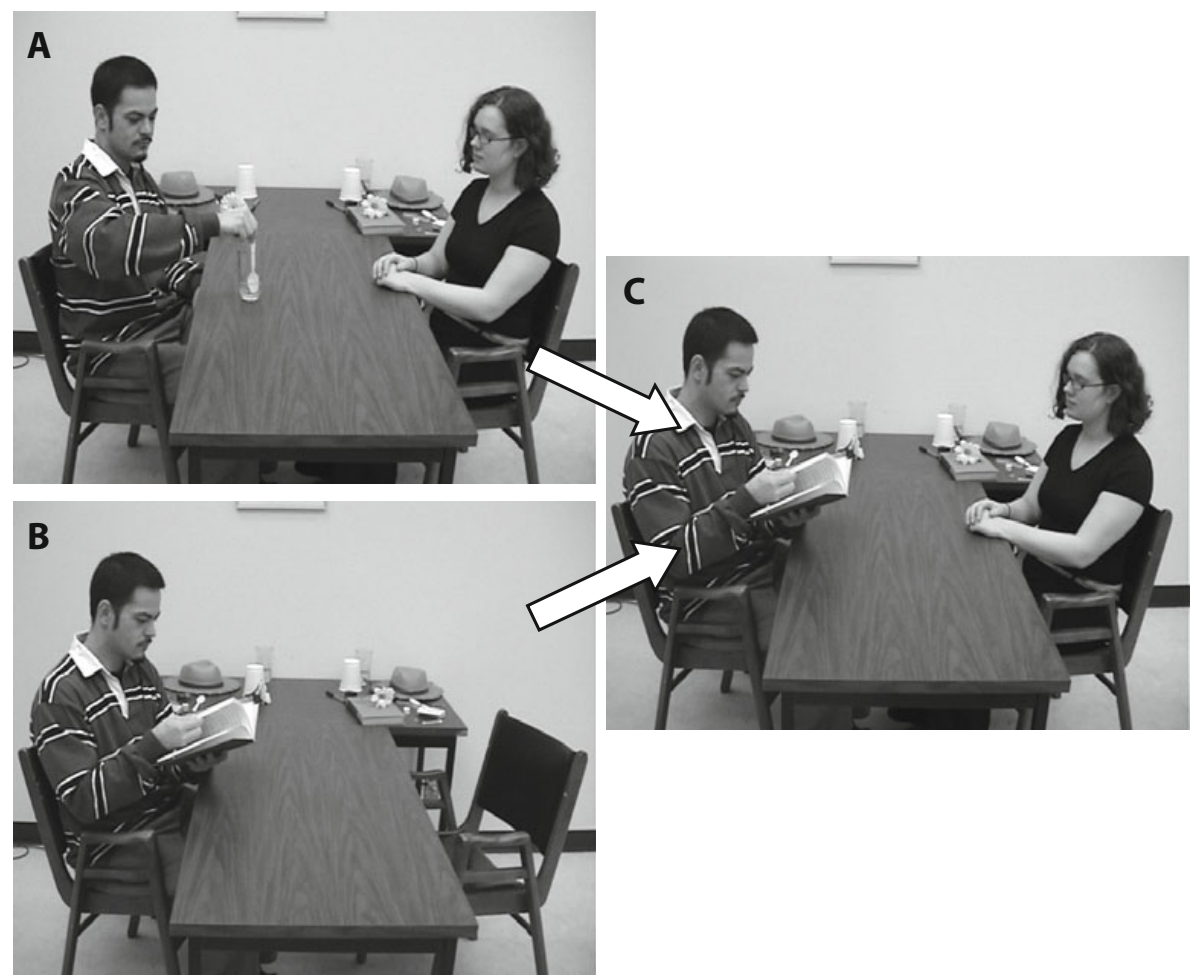

Figure 1. The video-doctoring process. (A) The subject (right) observes the research assistant (RA) perform an action during Session 1. (B) The RA performs an extra action after the subject has gone. (C) Composite of the right side of panel $A$ and the left side of panel $B$.

\section{Results and Discussion}

\section{Subjects' Acceptance of the Video Evidence}

Several reasons led us to be confident that subjects were unaware of the true nature of the experiment. First, no subject reported that the aim of the study was to investigate the effects of false video evidence. Second, many subjects indicated that they were surprised that the video had been edited ("It was changed? I didn't notice that at all!"; "Oh, it was? I didn't have a clue!"). Third, $47 \%$ of subjects failed to identify either of the critical video actions. On average, subjects identified 0.66 out of 2 critical actions. Together, these findings suggest that subjects generally accepted the video as an accurate record.

Nevertheless, although no subjects claimed that the video was edited, some appeared to suspect that they were being tricked. We categorized subjects as suspicious if they indicated at any stage that there were actions in the video that they did not think they performed or if they successfully identified both critical video actions. The 12 subjects who met these criteria did not differ significantly from other subjects in their belief or memory ratings for any critical action type (smallest nonadjusted $p=.061$ ); thus, the following analyses include data from all 47 subjects.

\section{Belief and Memory Rating}

We now turn to our primary questions. First, was doctored video evidence alone sufficient to change subjects' beliefs and memories? Figure 2 shows that it was: Subjects rated video-only actions higher than control actions on both the belief $\left[t(46)=3.50, p<.01, d_{z}=.51\right]$ and memory $\left[t(46)=2.17, p=.04, d_{z}=.32\right]$ scales. Second, did the imagination or false evidence technique have

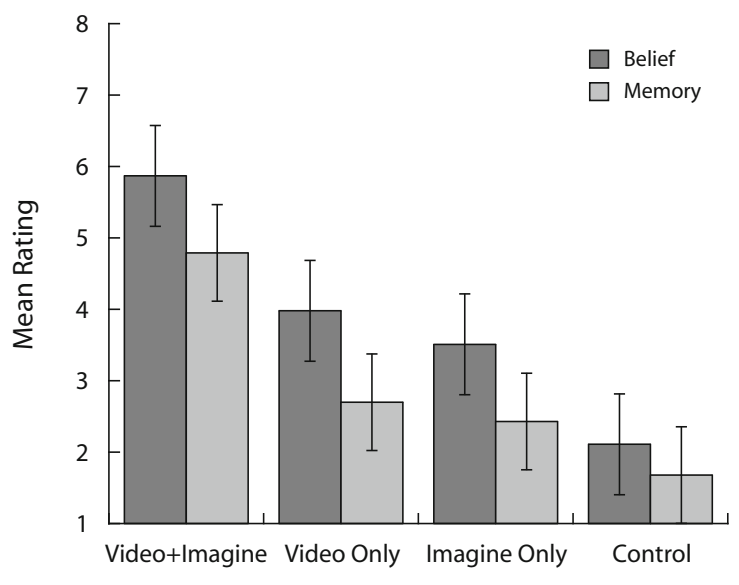

Condition

Figure 2. Mean belief and memory ratings across conditions in Experiment 1. Error bars represent $95 \%$ within-subjects confidence intervals (G. R. Loftus \& Masson, 1994). 
Table 1

Predicted and Observed Mean Ratings for Video+Imagine Actions in Experiments 1 and 2

\begin{tabular}{lccc}
\hline & $\begin{array}{c}\text { Predicted } \\
\text { Mean Rating }\end{array}$ & $\begin{array}{c}\text { Observed } \\
\text { Mean Rating }\end{array}$ & $\begin{array}{c}p \text { (One-Sample } \\
t \text { Test })\end{array}$ \\
\hline $\begin{array}{l}\text { Experiment 1 } \\
\text { Belief }\end{array}$ & 5.38 & 5.87 & .20 \\
$\quad$ Memory & 3.45 & 4.79 & .002 \\
Experiment 2 & & & \\
$\quad$ Belief & 6.13 & 6.15 & .96 \\
Memory & 4.83 & 4.94 & .77 \\
\hline
\end{tabular}

greater influence on beliefs and memories? Our data suggest that, in isolation, the two techniques had equivalent effects: Both influenced beliefs and memories (although the difference between imagine-only and control actions on the memory measure did not reach conventional significance $\left[t(46)=1.73, p=.09, d_{z}=.25\right]$, and there were no differences between video-only and imagine-only actions on the belief $\left[t(46)=0.94, p=.35, d_{z}=.14\right]$ or memory $\left[t(46)=0.60, p=.55, d_{z}=.09\right]$ scale. The present results lead us to conclude that watching a 10-sec doctored video clip was just as hazardous as imagining a critical action for $40 \mathrm{sec}$.

Finally, by looking more closely at the data represented in Figure 2 to examine how false evidence and imagination interact, we can speculate about the mechanisms responsible for the false evidence effect. ${ }^{2}$ Two 2 (video vs. no video) $\times 2$ (imagined vs. not imagined) withinsubjects ANOVAs revealed no significant interactions on either belief or memory, although the interaction for memory ratings approached the conventional significance level [belief, $F(1,46)=0.40, p=.53, \eta_{\mathrm{p}}^{2}=.01,95 \% \mathrm{CI}=$ $.00 \leq \eta_{\mathrm{p}}^{2} \leq .12$; memory, $F(1,46)=3.46, p=.07, \eta_{\mathrm{p}}^{2}=$ $\left..07,95 \% \mathrm{CI}=.00 \leq \eta_{\mathrm{p}}^{2} \leq .24\right] .{ }^{3}$ These null interactions suggest that the combined effects of the two techniques were additive. However, because there was a tendency toward a superadditive combined effect for memory and because of the problems inherent in inferring additivity from a null interaction, we conducted some additional analyses to further examine these data. We calculated the mean video + imagine ratings that should be predicted given an additive combined effect, by adding the mean ratings for video-only and imagine-only actions, and subtracting the mean control rating from this value (note that video- and imagine-only ratings each comprise a unique effect plus a baseline, equivalent to the mean control rating). Table 1 shows that our observed video+imagine memory ratings were significantly greater than the predicted mean, whereas the belief ratings did not differ significantly. In short, although the analyses generally support an additive account of the effects of false evidence and imagination, there was nevertheless some indication that the two effects may have combined superadditively. We will return to these findings in the General Discussion section.

\section{Memorability}

To examine whether our memorability manipulation affected subjects' belief and memory ratings, we classified the two more memorable critical actions (kiss the magnifying glass, rub the Q-tip on the toy car) as highmemorability actions and the two less memorable critical actions (roll the dice, browse the book) as low-memorability actions. Across all conditions, subjects gave higher belief $[t(186)=2.85, p=.005, d=.42]$ and memory $[t(186)=$ $2.112, p=.04, d=.31]$ ratings to low-memorability actions than to high-memorability actions (the totals are listed in Table 2); therefore, our subjects could to some extent use a memorability-based strategy to identify critical actions that they would not expect to forget performing (Ghetti, 2003; Mazzoni \& Kirsch, 2002).

How did imagination and false evidence affect subjects' belief and memory ratings for low- and high-memorability actions? Recall that both imagination and false evidence increased subjects' ratings overall (the totals are listed in Table 2). Our memorability analyses in Table 2 showed that this pattern was true of both low- and high-memorability actions. Put differently, imagining an action or seeing it in the doctored video caused similar levels of belief and memory distortion for high-memorability actions as they did for low-memorability actions (for all interactions, $p>.19 ;$ all $\left.\eta_{\mathrm{p}}^{2} \mathrm{~s}<.01\right)$.

\section{Summary}

Even without imagination, our doctored videos were sufficient to cause significant belief and memory distortions. Doctored videos appeared to be at least as powerful as imagination, and when the two forms of suggestion were combined, they had an additive or superadditive effect. The large distortive effects found in previous false

Table 2

Mean Belief and Memory Ratings As a Function of Memorability and of Presence or Absence of Video and Imagination

Memorability

\begin{tabular}{|c|c|c|c|c|c|c|c|c|c|c|c|c|}
\hline & \multicolumn{12}{|c|}{ Memorability } \\
\hline & \multicolumn{6}{|c|}{ Belief } & \multicolumn{6}{|c|}{ Memory } \\
\hline & \multicolumn{2}{|c|}{ High } & \multicolumn{2}{|c|}{ Low } & \multicolumn{2}{|c|}{ Total } & \multicolumn{2}{|c|}{ High } & \multicolumn{2}{|c|}{ Low } & \multicolumn{2}{|c|}{ Total } \\
\hline & $M$ & $S D$ & $M$ & $S D$ & $M$ & $S D$ & $M$ & $S D$ & $M$ & $S D$ & $M$ & $S D$ \\
\hline No video & 2.30 & 2.23 & 3.32 & 2.49 & 2.81 & 2.40 & 1.85 & 2.16 & 2.26 & 2.19 & 2.05 & 2.17 \\
\hline Video & 4.30 & 2.77 & 5.55 & 2.63 & 4.93 & 2.76 & 3.15 & 2.79 & 4.36 & 2.74 & 3.76 & 2.82 \\
\hline Not imagined & 2.30 & 2.09 & 3.79 & 2.69 & 3.04 & 2.51 & 1.55 & 1.53 & 2.83 & 2.51 & 2.19 & 2.17 \\
\hline Imagined & 4.30 & 2.87 & 5.09 & 2.74 & 4.69 & 2.82 & 3.45 & 3.02 & 3.79 & 2.79 & 3.62 & 2.90 \\
\hline Total & 3.30 & 2.70 & 4.44 & 2.78 & 3.87 & 2.79 & 2.50 & 2.56 & 3.31 & 2.68 & 2.90 & 2.65 \\
\hline
\end{tabular}

Note-Each row represents mean ratings for two critical actions combined. For example, the no video data combine ratings for imagine-only and control actions. 
evidence studies may, therefore, be just as attributable to the imagination tasks that subjects were given as to the false evidence itself. Moreover, both suggestive techniques in Experiment 1 increased subjects' belief in lowand in high-memorability actions, providing evidence that the techniques' effects are not limited to forgettable experiences.

\section{EXPERIMENT 2}

Experiment 2 examined whether the effects of imagination and false evidence would persist if subjects were warned that videos can be easily tampered with and that imagining counterfactual events can inflate one's confidence. In the false memory literature, a handful of studies have investigated the influence of warnings on subjects' resistance to suggestion, and the results have been mixed. In the misinformation domain, Greene, Flynn, and Loftus (1982) found that warning subjects before, but not after, they were exposed to misinformation helped them to resist suggestion. Chambers and Zaragoza (2001), however, found that warnings helped subjects regardless of when they were delivered. In studies of the DRM effect, pre-encoding warnings robustly reduced the rate of false memories, whereas the efficacy of postencoding warnings depended on other variables (e.g., Gallo, Roediger, \& McDermott, 2001; McCabe \& Smith, 2002; Watson, McDermott, \& Balota, 2004). Two studies of greatest relevance to the present research have also found mixed results: Landau and von Glahn (2004) found that subjects who received warnings about imagination exhibited a smaller inflation effect than those who received no warning; whereas a study from the communications literature (Kelly \& Nace, 1994) revealed that warnings about the capabilities of digital editing software failed to reduce subjects' belief in news articles and photos from disreputable sources. Taken as a whole, these studies show that warnings, especially postencoding warnings, work under certain conditions but not others. For now, it is not clear when warnings protect subjects from the effects of suggestive techniques.

\section{Method}

\section{Subjects and Design}

Forty-eight University of Warwick (United Kingdom) undergraduates received $£ 8$ for participating in three sessions over 13-16 days $(M=14.83$ days, $S D=1.02)$. We used a 2 (video vs. no video $) \times 2$ (imagined vs. not imagined) within-subjects design, and added a 2 (video warning vs. no video warning) $\times 2$ (imagination warning vs no imagination warning) between-subjects manipulation. Subjects were randomly allocated to warning conditions.

\footnotetext{
Materials and Procedure

Selecting the critical and noncritical actions. We selected 45 of Goff and Roediger's (1998) nonobject actions (listed in Appendix B) and, because we did not manipulate memorability in Experiment 2, from those we chose four critical actions that 25 volunteers rated as moderately memorable on a 7-point scale, where $1=I^{\prime} d$ easily remember doing this and $7=$ I'd easily forget doing this. The critical actions were clap your hands $(M=4.68, S D=1.93)$, salute $(M=4.44, S D=1.58)$, click your fingers $(M=4.56, S D=2.22)$,
}

and flex your arm $(M=5.04, S D=1.64)($ all $p \mathrm{~s}>.05)$. The remaining 41 actions served as noncritical (filler) actions at various stages of the experiment.

The warnings. Video warning. The video warning served to prime subjects' knowledge about digital image editing. We modified a warning from Dreifus (2007) to the following:

In society today, we're now seeing doctored photos and doctored videos regularly. For example, if tabloids can't obtain a photo of Brad Pitt and Angelina Jolie walking together on a beach, they'll make up a composite from two pictures. As a result, we now live in an age when the once-held belief that photographs and videos were reliable records of events is now gone.

Imagination warning. The imagination warning served to alert subjects to the possibility that a clear memory-like mental image could be an imagined event. We modified Landau and von Glahn's (2004) warning to the following:

Imagining has been found to alter people's confidence that they performed an action. This happens because after imagining, people often don't carefully scrutinize their memory to decide whether the action was real or imagined. In other words, people are often more likely to believe they performed an action if they imagined doing it, because they confuse the details of the imagined memory as real.

Session 1 (event phase) and Session 2 (suggestion phase). The present sessions were similar to those in Experiment 1 with minor changes: To increase the pace of the task in Session 1, the RA and the subject performed each action for 12 rather than $15 \mathrm{sec}$. In Session 2, we shortened the gaps between clips in the video sequence used to 10 rather than $15 \mathrm{sec}$. Finally, subjects imagined 64, rather than 60 , actions in the imagination task in Session 2.

Session 3: Memory test. The memory test was similar to that used in Experiment 1. Prior to completing the memory test, subjects (except no-warning subjects) were exposed to the appropriate warning(s). They listened to recordings of the warning(s) and simultaneously viewed the written warning(s) on a computer monitor. Finally, subjects were instructed to consider the warning(s) as they completed the memory test.

\section{Results and Discussion}

Once again, subjects appeared to be unaware that the video had been edited, and they expressed surprise when they discovered the real purpose of the study. Only $17 \%$ correctly identified one of the critical video actions, and no subject correctly identified both. Only 1 subject (one of those who received the video warning) speculated that the study was investigating false evidence; this is surprising given that $50 \%$ of subjects received the video warning.

\section{The Effects of Warnings}

We conducted two 2 (video vs. no video) $\times 2$ (imagined vs. not imagined) $\times 2$ (video warning vs. no video warning) $\times 2$ (imagination warning vs. no imagination warning) mixed-factor ANOVAs. The present analyses revealed no significant interactions or main effects involving the warning variables on either the belief or the memory measure (all $p \mathrm{~s}>.23$, largest $\eta_{\mathrm{p}}^{2}=.03$; see Table 3 ). However, there was a nonsignificant tendency for video-warning subjects to report lower ratings for the critical video actions than did novideo-warning subjects (pooling across the video + imagine and video-only actions, $d_{\text {belief }}=.27$ and $d_{\text {memory }}=.32$ ). Despite this trend, video-warning subjects still reported moderately high levels of belief $(M=5.08)$ and memory 
Table 3

Mean Belief and Memory Ratings As a Function of the Presence or Absence of Each Warning Type

\begin{tabular}{|c|c|c|c|c|c|c|c|c|}
\hline \multirow[b]{2}{*}{ Warning Condition } & \multicolumn{2}{|c|}{$\begin{array}{l}\text { Video+ } \\
\text { Imagine }\end{array}$} & \multicolumn{2}{|c|}{ Video Only } & \multicolumn{2}{|c|}{$\begin{array}{l}\text { Imagine } \\
\text { Only }\end{array}$} & \multicolumn{2}{|c|}{ Control } \\
\hline & $M$ & $S D$ & $M$ & $S D$ & $M$ & $S D$ & $M$ & $S D$ \\
\hline \multicolumn{9}{|l|}{ Belief } \\
\hline No video warning & 6.46 & 2.06 & 5.00 & 2.50 & 4.08 & 2.38 & 2.79 & 1.72 \\
\hline Video warning & 5.83 & 2.33 & 4.33 & 2.79 & 4.29 & 2.40 & 2.67 & 1.58 \\
\hline No imagination warning & 6.00 & 2.52 & 4.71 & 2.42 & 4.21 & 2.17 & 2.54 & 1.38 \\
\hline Imagination warning & 6.29 & 1.88 & 4.63 & 2.90 & 4.17 & 2.60 & 2.92 & 1.86 \\
\hline \multicolumn{9}{|l|}{ Memory } \\
\hline No video warning & 5.46 & 2.38 & 3.88 & 2.64 & 2.92 & 2.43 & 1.71 & 1.33 \\
\hline Video warning & 4.42 & 2.71 & 3.25 & 2.69 & 3.00 & 2.47 & 1.67 & 1.52 \\
\hline No imagination warning & 5.25 & 2.59 & 3.63 & 2.48 & 3.04 & 2.22 & 1.58 & 1.21 \\
\hline Imagination warning & 4.63 & 2.58 & 3.50 & 2.87 & 2.88 & 2.66 & 1.79 & 1.62 \\
\hline
\end{tabular}

Note-Each row represents mean ratings for two warning conditions. For example, the no-videowarning data combine ratings for imagination-warning-only and no-warning subjects. $N=24$ for each row.

$(M=3.83)$ for the two critical video actions. The present findings lead us to conclude that, although explicit information about digital editing might prompt people to evaluate their beliefs and memories more systematically, the warning in the present experiment, as in Kelly and Nace's (1994) study, was insufficient to protect subjects from distortions. A stronger or more explicit warning, therefore, might reveal an effect. Our findings contrast with those of Landau and von Glahn (2004), whose results suggest that subjects should have successfully used the imagination warning to resist belief and memory distortions.

Why did our warnings fail to influence subjects' belief and memory ratings significantly? One possibility is that many subjects simply did not recognize the information as a warning per se. Indeed, most video-warning subjects did not guess the purpose of the study, which suggests that they were not particularly suspicious. This proposition raises an interesting question for future research on warnings: Do warnings protect people from misinformation only if they already suspect that they may have been misled? Moreover, although Landau and von Glahn (2004) effectively reduced imagination inflation by warning subjects after they imagined events, it is likely that, as in Greene et al.'s (1982) study and the DRM warning studies cited above, our warnings would have been more effective if subjects received them before seeing the doctored video and imagining.

\section{Belief and Memory Rating}

As Figure 3 shows, we replicated the pattern of results obtained in Experiment 1. Doctored videos alone were sufficient to change subjects' beliefs and memories: Subjects rated video-only actions higher than control actions on the belief $\left[t(47)=4.35, p<.001, d_{z}=.63\right]$ and memory $\left[t(47)=4.30, p<.001, d_{z}=.62\right]$ scales. Similarly, they rated imagine-only actions higher than they did control actions on the belief $\left[t(47)=3.87, p<.001, d_{z}=.56\right]$ and memory $\left[t(47)=3.79, p<.001, d_{z}=.55\right]$ scales. The differences between video- and imagine-only actions were not significant on either measure [belief, $t(47)=0.89, p=$ $.38, d_{z}=.13$; memory, $\left.t(47)=1.10, p=.28, d_{z}=.16\right]$.
The mixed-factor ANOVAs for the within-subjects effects represented in Figure 3 revealed no significant interactions of imagination and false evidence upon belief $\left[F(1,44)=0.001, p=.97, \eta_{\mathrm{p}}^{2}<.01,95 \% \mathrm{CI}=.00 \leq\right.$ $\left.\eta_{\mathrm{p}}^{2} \leq .0001\right]$ or memory $\left[F(1,44)=0.04, p=.85, \eta_{\mathrm{p}}^{2}<\right.$ $.01,95 \% \mathrm{CI}=.00 \leq \eta_{\mathrm{p}}^{2} \leq .03$ ] ratings, suggesting that the effects operated additively. A further demonstration of this additivity comes from the data in Table 1, which show that subjects' mean belief and memory ratings for video + imagine actions were extremely similar to those predicted by the independent effects of the doctored video and imagination.

\section{Summary}

Experiment 2 provides further evidence that imagination can influence people's beliefs and memories about self-involving, recent actions, but so too can false evi-

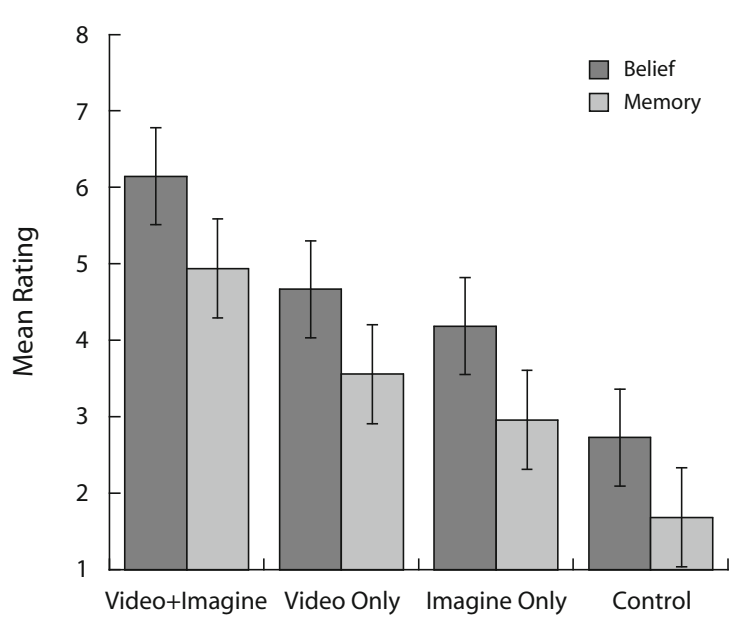

Condition

Figure 3. Mean belief and memory ratings across conditions in Experiment 2. Error bars represent 95\% within-subjects confidence intervals (G. R. Loftus \& Masson, 1994). 
dence. Moreover, the combination of these techniques leads to significantly more belief and memory distortion than does either technique alone, with the two effects appearing to be additive. Finally, neither an explicit postsuggestion warning about digital image editing nor a warning about imagination inflation was sufficient to significantly reduce these effects.

\section{GENERAL DISCUSSION}

In two experiments, we assessed the individual and combined contributions of imagination and false evidence to the distortion of beliefs and memories. We found that both forms of suggestion are considerably influential. The present experiments are the first to demonstrate that false evidence can create false memories of recent actions. Consistent with the findings from distant (childhood) memory studies (e.g., Wade et al., 2002), less than 2 weeks after seeing our doctored videos, many subjects confidently reported performing the suggested actions ("Those [the critical video actions] were particularly clear in my mind that I did them. I was $100 \%$ clear!"). Whereas Wade and colleagues' false evidence actually depicted subjects performing the fictional act (Garry \& Wade, 2005; Nash \& Wade, 2009; Wade et al., 2002), and other authors have used explicit and affirmative verbal feedback as evidence (Bernstein et al., 2005b; Desjardins \& Scoboria, 2007), the false evidence in the present study was less explicit. Indeed, subjects neither saw themselves perform the critical actions, nor did they receive a verbal suggestion. This implicit trickery was highly effective despite the fact that over half of subjects in Experiment 2 (58.3\%) reported having used digital-editing software in the past.

The combined effects of imagination and false evidence enable us to speculate about how false evidence might influence beliefs and memories. Certainly, there was no indication in either experiment that imagination and false evidence have subadditive effects. This finding suggests that the false evidence effect is not caused by the videos' ability to help people to imagine counterfactual events, because the effect of imagining typically diminishes as one's mental imagery becomes more detailed (Goff \& Roediger, 1998; Henkel \& Carbuto, 2008; Thomas \& Loftus, 2002). Rather, our findings of additivity are most supportive of a criterion-based account of the false evidence effect. Guided by the SMF, Mazzoni and Kirsch (2002) proposed that autobiographical distortions are products of the combination of two factors: (1) a lowered memory criterion (i.e., lower expectations for the amount of memorial information required to treat a mental experience as a memory) and (2) enhanced mental imagery. Doctored videos, we expect, provide the first of these two factors in that they cause subjects to lower their criteria for treating images as true memories, whereas imagination provides the second. This criteria-based interpretation of our findings can be reframed as follows: Sometimes our subjects experienced false memories if their mental imagery quality was poor, but they had cause to adopt low criteria (video only); similarly, they sometimes experienced false memories if they had high criteria, but their mental imagery quality was also high (imagine only). However, subjects were naturally most susceptible to false memories if they had cause to adopt low criteria and their mental imagery quality was high (video + imagine).

Nevertheless, some evidence obtained in Experiment 1 indicated a superadditive combined effect. Because imagining plausible events causes more memory distortion than does imagining implausible events (Pezdek et al., 2006), it is likely that superadditivity would occur if false evidence works by increasing the perceived plausibility of suggestions. Perhaps, then, the critical actions in Experiment 2, which could well have been more plausible than those in Experiment 1, might be the reason we did not replicate the evidence of superadditivity obtained in Experiment 1. Future research should examine more directly the mechanisms that drive the false evidence effect.

Our findings have practical implications beyond understanding the mechanisms responsible for false beliefs and memories, and they raise several important questions for future research. For instance, can video evidence induce people to testify about events that never happened? This is a question we are currently investigating, and we know of at least one real-life case that speaks to this issue. E. F. Loftus and Guyer (2002) have discussed the case of "Jane Doe," who apparently recovered memories of abuse during a clinical interview in which she viewed an 11-year-old video of herself recounting those traumatic events (see also Corwin \& Olafson, 1997). Although the validity of Jane Doe's memories has never been proved (or disproved), there is no doubt that seeing the video played a crucial part in persuading Doe that her original accusations were genuine. The videotape shown to Doe would have provided her with two cues: ostensibly clear evidence that she was abused and vivid childhood imagery such as her appearance at the time. The results of the present study suggest that these two cues are sometimes sufficient for people to create clear false memories of completely fictional events.

Furthermore, does imagination boost the impact of false evidence in eliciting false confessions from criminal suspects? Several studies have shown that presenting innocent subjects with false evidence-a legal interrogation technique used in some countries to elicit confessions (Gudjonsson, 2003) - can increase their likelihood of falsely confessing to and internalizing guilt for a punishable act (Kassin \& Kiechel, 1996; Nash \& Wade, 2009). To the best of our knowledge, no false confession study to date has involved instructing subjects to imagine the "crime" after exposure to false evidence, most likely because of the ethical concerns that such a procedure might raise. Our results suggest that the combination of imagination and false evidence in criminal interrogations might be particularly powerful in eliciting internalized false confessions or even false memories of committing a crime.

False evidence can, in effect, change the past. In the present article, we have shown that even our memories of recent, self-involving events can be modified by subtle and compelling digital trickeries, as well as by imagination, with the two forms of suggestion combining to cause remarkably high levels of belief and memory distortion. The limits of the false evidence effect remain to be seen. 


\section{AUTHOR NOTE}

We thank Sara Cowan for modeling for Figure 1 and Jeffrey Sun, Olwen Bryer, Emily Froom-Hodgson, Tamara Meixner, and Melissa Thompson for their assistance in data collection. We are grateful to John Seamon and two anonymous reviewers for their helpful comments and suggestions. Correspondence concerning this article should be addressed to K. A. Wade, Department of Psychology, University of Warwick, Coventry CV4 7AL, England (e-mail: k.a.wade@warwick.ac.uk).

\section{REFERENCES}

Bernstein, D. M., Laney, C., Morris, E. K., \& Loftus, E. F. (2005a). False beliefs about fattening foods can have healthy consequences. Proceedings of the National Academy of Sciences, 102, 13724-13731.

Bernstein, D. M., Laney, C., Morris, E. K., \& Loftus, E. F. (2005b). False memories about food can lead to food avoidance. Social Cognition, 23, 11-34. doi:10.1521/soco.23.1.11.59195

Chambers, K. L., \& Zaragoza, M. S. (2001). Intended and unintended effects of explicit warnings on eyewitness suggestibility: Evidence from source identification tests. Memory \& Cognition, 29, 1120-1129.

Corwin, D. L., \& Olafson, E. (1997). Videotaped discovery of a reportedly unrecallable memory of child sexual abuse: Comparison with a childhood interview videotape 11 years before. Child Maltreatment, 2, 91-112. doi: $10.1177 / 1077559597002002001$

Desjardins, T., \& Scoboria, A. (2007). "You and your best friend Suzy put Slime in Ms. Smollett's desk": Producing false memories with selfrelevant details. Psychonomic Bulletin \& Review, 14, 1090-1095.

Dreifus, C. (2007, October 2). Proving that seeing shouldn't always be believing. New York Times, p. D2.

FinKe, R. A., Johnson, M. K., \& Shyi, G. C. (1988). Memory confusions for real and imagined completions of symmetrical visual patterns. Memory \& Cognition, 16, 133-137.

Gallo, D. A., Roediger, H. L., III, \& McDermott, K. B. (2001). Associative false recognition occurs without strategic criterion shifts. Psychonomic Bulletin \& Review, 8, 579-586.

Garry, M., Manning, C. G., Loftus, E. F., \& Sherman, S. J. (1996). Imagination inflation: Imagining a childhood event inflates confidence that it occurred. Psychonomic Bulletin \& Review, 3, 208-214.

Garry, M., \& PolascheK, D. L. L. (2000). Imagination and memory. Current Directions in Psychological Science, 9, 6-10. doi:10.1111/1467-8721.00048

GARRY, M., \& WADE, K. A. (2005). Actually, a picture is worth less than 45 words: Narratives produce more false memories than photographs do. Psychonomic Bulletin \& Review, 12, 359-366.

Geraerts, E., Bernstein, D. M., Merckelbach, H., Linders, C., RaYmaekers, L., \& Loftus, E. F. (2008). Lasting false beliefs and their behavioral consequences. Psychological Science, 19, 749-753. doi: $10.1111 / j .1467-9280.2008 .02151 . x$

GhetTI, S. (2003). Memory for nonoccurrences: The role of metacognition. Journal of Memory \& Language, 48, 722-739. doi:10.1016/ S0749-596X(03)00005-6

GoFf, L. M., \& Roediger, H. L., III (1998). Imagination inflation for action events: Repeated imaginings lead to illusory recollections. Memory \& Cognition, 26, 20-33.

Greene, E., FlynN, M., \& Loftus, E. F. (1982). Inducing resistance to misleading information. Journal of Verbal Learning \& Verbal Behavior, 21, 207-219. doi:10.1016/S0022-5371(82)90571-0

Gudjonsson, G. H. (2003). The psychology of interrogations and confessions. Chichester, U.K.: Wiley.

HART, R. E., \& SCHOOLER, J. W. (2006). Increasing belief in the experience of an invasive procedure that never happened: The role of plausibility and schematicity. Applied Cognitive Psychology, 20, 661-669. doi:10.1002/acp. 1218

Henkel, L. A., \& Carbuto, M. (2008). Remembering what we did: How source misattributions arise from verbalization, mental imagery, and pictures. In M. R. Kelley (Ed.), Applied memory (pp. 213-234). Haupauge, NY: Nova Science Publishers.

Hyman, I. E., JR., Husband, T. H., \& Billings, F. J. (1995). False memories of childhood experiences. Applied Cognitive Psychology, 9, 181197. doi:10.1002/acp.2350090302

Hyman, I. E., JR., \& Pentland, J. (1996). The role of mental imagery in the creation of false childhood memories. Journal of Memory \& Language, 35, 101-117. doi:10.1006/jmla.1996.0006

Johnson, M. K., Foley, M. A., Suengas, A. G., \& RaYe, C. L. (1988) Phenomenal characteristics of memories for perceived and imagined autobiographical events. Journal of Experimental Psychology: General, 117, 371-376. doi:10.1037/0096-3445.117.4.371

Johnson, M. K., Hashtroudi, S., \& Lindsay, D. S. (1993). Source monitoring. Psychological Bulletin, 114, 3-28. doi:10.1037/0033 $-2909.114 .1 .3$

Johnson, M. K., \& RAYE, C. L. (1981). Reality monitoring. Psychological Review, 88, 67-85. doi:10.1037/0033-295X.88.1.67

JoHnson, M. K., \& RAYE, C. L. (2000). Cognitive and brain mechanisms of false memories and beliefs. In D. L. Schacter \& E. Scarry (Eds.), Memory, brain, and belief (pp. 35-86). Cambridge, MA: Harvard University Press.

Johnson, M. K., RaYe, C. L., WANG, A. Y., \& TAYlor, T. H. (1979). Fact and fantasy: The roles of accuracy and variability in confusing imaginations with perceptual experiences. Journal of Experimental Psychology: Learning, Memory, \& Cognition, 5, 229-240. doi:10.1037/0278-7393.5.3.229

Kassin, S. M., \& Kiechel, K. L. (1996). The social psychology of false confessions: Compliance, internalization, and confabulation. Psychological Science, 7, 125-128. doi:10.1111/j.1467-9280.1996 .tb00344.x

KelLy, J. E., \& NACE, D. (1994). Digital imaging and believing photos. Visual Communication Quarterly, 1, 4-7.

LANDAU, J. D., \& VON GLAHN, N. (2004). Warnings reduce the magnitude of the imagination inflation effect. American Journal of Psychology, 117, 579-593. doi:10.2307/4148993

LinDSAY, D. S. (2008). Source monitoring. In J. H. Byrne (Series Ed.) \& H. L. Roediger III (Vol. Ed.), Learning and memory: A comprehensive reference. Vol. 2: Cognitive psychology of memory (pp. 325-348). Amsterdam: Elsevier.

Lindsay, D. S., Hagen, L., Read, J. D., Wade, K. A., \& Garry, M. (2004). True photographs and false memories. Psychological Science, 15, 149-154. doi:10.1111/j.0956-7976.2004.01503002.x

Loftus, E. F., \& GuYer, M. J. (2002, May/June). Who abused Jane Doe? The hazards of the single case history, Part I. Skeptical Inquirer, 26, 24-32

LoftUs, E. F., \& PALmer, J. C. (1974). Reconstruction of automobile destruction: An example of the interaction between language and memory. Journal of Verbal Learning \& Verbal Behavior, 13, 585-589. doi:10.1016/S0022-5371(74)80011-3

Loftus, E. F., \& Pickrell, J. E. (1995). The formation of false memories. Psychiatric Annals, 25, 720-725.

Loftus, G. R. (1978). On interpretation of interactions. Memory \& Cognition, 6, 312-319.

Loftus, G. R., \& Masson, M. E. J. (1994). Using confidence intervals in within-subjects designs. Psychonomic Bulletin \& Review, 1, 476-490.

Lynn, S. J., Pintar, J., Stafford, J., Marmelstein, L., \& Lock, T. (1998). Rendering the implausible plausible: Narrative construction, suggestion, and memory. In J. de Rivera \& T. R. Sarbin (Eds.), Believed-in imaginings: The narrative construction of reality ( pp. 123143). Washington, DC: American Psychological Association.

Mazzoni, G., \& KIRSCH, I. (2002). Autobiographical memories and beliefs: A preliminary metacognitive model. In T. J. Perfect \& B. L. Schwartz (Eds.), Applied metacognition (pp. 121-145). Cambridge: Cambridge University Press.

Mazzoni, G., \& Memon, A. (2003). Imagination can create false autobiographical memories. Psychological Science, 14, 186-188. doi:10.1046/j.1432-1327.2000.01821.x

McCABE, D. P., \& SMith, A. D. (2002). The effect of warnings on false memories in young and older adults. Memory \& Cognition, 30, 10651077.

NASH, R. A., \& WADE, K. A. (2009). Innocent but proven guilty: Eliciting internalized false confessions using doctored-video evidence. $A p$ plied Cognitive Psychology, 23, 624-637. doi:10.1002/acp.1500

Pezdek, K., Blandon-Gituin, I., \& GabBay, P. (2006). Imagination and memory: Does imagining implausible events lead to false autobiographical memories? Psychonomic Bulletin \& Review, 13, 764769.

Pezdek, K., Finger, K., \& Hodge, D. (1997). Planting false childhood 
memories: The role of event plausibility. Psychological Science, $\mathbf{8}$, 437-441. doi:10.1111/j.1467-9280.1997.tb00457.x

PezDEK, K., \& LaM, S. (2007). What research paradigms have cognitive psychologists used to study "false memory," and what are the implications of these choices? Consciousness \& Cognition, 16, 2-17. doi:10.1016/j.concog.2005.06.006

Roediger, H. L., III, \& MCDermotT, K. B. (1995). Creating false memories: Remembering words not presented in lists. Journal of Experimental Psychology: Learning, Memory, \& Cognition, 21, 803-814. doi:10.1037/0278-7393.21.4.803

Scoboria, A., Mazzoni, G., Kirsch, I., \& Relyea, M. (2004). Plausibility and belief in autobiographical memory. Applied Cognitive Psychology, 18, 791-807. doi:10.1002/acp.1062

Seamon, J. G., Philbin, M. M., \& Harrison, L. G. (2006). Do you remember proposing marriage to the Pepsi machine? False recollections from a campus walk. Psychonomic Bulletin \& Review, 13, 752-756.

Thomas, A. K., Bulevich, J. B., \& Loftus, E. F. (2003). Exploring the role of repetition and sensory elaboration in the imagination inflation effect. Memory \& Cognition, 31, 630-640.

Thomas, A. K., \& LofTus, E. F. (2002). Creating bizarre false memories through imagination. Memory \& Cognition, 30, 423-431.

Tousignant, J. P., Hall, D., \& LofTus, E. F. (1986). Discrepancy detection and vulnerability to misleading postevent information. Memory \& Cognition, 14, 329-338.

WADE, K. A., \& GARRY, M. (2005). Strategies for verifying false autobiographical memories. American Journal of Psychology, 118, 587-602.

WAdE, K. A., Garry, M., Read, J. D., \& LindSAy, D. S. (2002). A pic- ture is worth a thousand lies: Using false photographs to create false childhood memories. Psychonomic Bulletin \& Review, 9, 597-603.

Wade, K. A., Sharman, S. J., Garry, M., Memon, A., Mazzoni, G., Merckelbach, H., \& Loftus, E. F. (2007). False claims about false memory research. Consciousness \& Cognition, 16, 18-28. doi:10.1016/j.concog.2006.07.001

Watson, J. M., McDermott, K. B., \& Balota, D. A. (2004). Attempting to avoid false memories in the Deese/Roediger-McDermott paradigm: Assessing the combined influence of practice and warnings in young and old adults. Memory \& Cognition, 32, 135-141.

\section{NOTES}

1. Subjects returned for Session 3 according to their availability. When we conducted analyses that included only the subjects who completed the study within \pm 2 days of the 15 -day ideal $(N=36)$, the pattern of results did not differ from the results presented.

2. Interpreting null and significant interactions always relies on the assumption that there are no scaling effects across levels of the dependent variables (G. R. Loftus, 1978). Nonetheless, exploring the pattern of effects is an important first step toward understanding joint effects. We followed the convention of treating the belief and memory scales as interval measures in order to analyze our data using parametric procedures, yet it is possible that these scales are ordinal measures.

3. We calculated confidence intervals for effect sizes using software provided by Mike Smithson. This software is available at http://psychology .anu.edu.au/people/smithson/details/CIstuff/CI.html.

\section{APPENDIX A}

Outline of Procedure

\section{Day 1: Event Phase}

Procedure: Subject is filmed observing and copying a research assistant (RA) who performs 26 noncritical actions. All subjects perform the same actions.

Subject leaves, and RA is then filmed performing two of the four critical actions. These video clips are used to create two of the critical actions (i.e., the video+imagine and video-only actions). They are doctored to depict the subject observing two actions she never observed or performed in the event phase.

\section{Day 3: Suggestion Phase}

Procedure:

1. Subject views video clips of herself observing actions during the event phase, including 10 noncritical actions that were performed in the event phase and 2 nonperformed critical actions (video+imagine; video only).

2. Subject imagines 15 actions (16 in Experiment 2) four times each, including 13 (14 in Experiment 2) noncritical and 2 nonperformed critical actions (video + imagine; imagine only).

The control action is not presented in this phase.

Critical actions:

\begin{tabular}{cc|c|c|}
\multicolumn{1}{c}{} & \multicolumn{2}{c}{ Action Imagined? } \\
\cline { 3 - 4 } & & Yes & No \\
\cline { 3 - 4 } Action in doctored video? & Yes & Video + Imagine & Video Only \\
\cline { 3 - 4 } & No & Imagine Only & Control \\
\cline { 3 - 4 } & & &
\end{tabular}

\section{Day 15 (Approximate): Memory Test}

Procedure: All subjects take the same recognition memory test consisting of 24 noncritical and 4 critical action statements (video+imagine; video only; imagine only; control).

- How likely is it that you performed this action? (belief)

- Do you actually remember performing this action? (memory) 


\section{APPENDIX B}

Action Lists

\section{Actions Used in Experiment 1}

Balance cards on the glass of water; Browse through the book; Clap your hands together; Click your fingers; Count to twenty; Cover your face with your hands; Do an impression of a monkey; Flap your arms up and down; Flex your arm; Flip the coin; Kiss the magnifying glass; Look through the magnifying glass; Make binoculars with your hands; Pick up the dice with the spoon; Play the air guitar; Pull a silly face; Pull the rubber band around the book; Push the toy car; Put on the hat; Put the empty cup over your ear; Rattle the coin in the empty cup; Recite the alphabet; Roll the dice; Rub the Q-tip on the toy car; Rub the Q-tip on your eyebrow; Rub the table; Salute; Scratch your nose; Shuffle the deck of cards; Smell the flower; Stand up and then sit down; Stir the water with the spoon; Stretch the rubber band; Tap the flower on your forehead; Throw the hat in the air; Touch your ear to your shoulder; Tug your earlobe; Wave good-bye.

\section{Actions Used in Experiment 2}

Bite your lip; Blow a kiss; Clap your hands; Clasp your hands together; Click your fingers; Count the fingers on one hand; Count to twenty; Cross your fingers; Cup your hand over your ear; Draw a stick man in the air; Fake a sneeze; Flex your arm; Fold your arms; Furrow your eyebrows; Lean over forward; Lick your lips; Look under the table; Look up toward the ceiling; Make a tight fist; Make binoculars with your hands; Nod in agreement; Play the piano on the desk; Point to your mouth; Raise your arms; Repeat 5914; Rest your head in your hands; Roll your eyes; Rub your eyes; Rub your stomach; Salute; Scratch your nose; Shake your head back and forth; Shrug your shoulders; Slap your thigh; Smooth your hair in the back; Stick out your tongue; Tap your wrist; Tilt back in the chair; Touch your cheek; Touch your ear to your shoulder; Touch your elbow with your thumb; Tug your earlobe; Turn around in a circle; Wave good-bye; Yawn. 